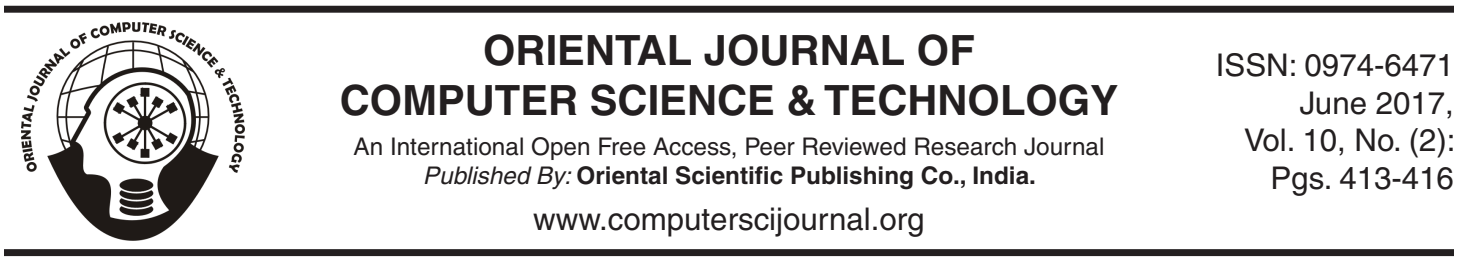

\title{
Comparative Study on Classification of Digital Images
}

\author{
H B BASANTH KUMAR \\ Pooja Bhagavat Memorial Mahajana Education Centre, KRS Road, Metagalli, Mysuru - 570016, India. \\ ${ }^{*}$ Corresponding author E-mail: basanth.10@gmail.com \\ http://dx.doi.org/10.13005/ojcst/10.02.22
}

(Received: April 20, 2017; Accepted: April 27, 2017)

\begin{abstract}
Digital images are widespread today. The use of digital images is classified into natural images and computer graphic images. Discrimination of natural images and computer graphic (CG) images are used in the applications which include flower classification, indexing of images, video classification and many more. With the rapid growth in the image rendering technology, the user can produce very high realistic computer graphic images using sophisticated graphics software packages. Due to high realism in CG images, it is very difficult for the user to distinguish it from natural images by a naked eye. This paper presents comparative study of the existing schemes used to classify digital images.
\end{abstract}

Keywords: Digital image, Natural image, Computer Graphic image, Classification.

\section{INTRODUCTION}

A digital image is the replica of the scene, what we see from the naked eye. It can be broadly classified into two categories: natural / photographic images and computer graphic images. A natural image is captured from digital camera or still camera while $C G$ images are produced from software's like MAYA, 3D studio max, light scape etc ${ }^{1}$. Recent development in the information technology allows the user to produce, manipulate and distribute the images over the network. This has raised the issue concerning the authenticity and integrity of digital images. CG images are very surrealistic in nature and it is similar to photographic images. Due to this reason, it is very tedious task to differentiate CG images from natural images ${ }^{2}$. To overcome this drawback various schemes have been proposed by the researchers.

Natural images and CG images are classified into three groups based on the features used by various researchers ${ }^{3}$ : The existing identification schemes can be classified into three categories according to the features used for identification ${ }^{3}$ :

\section{Physical features}

Physical features are the features generated at the time of image acquisition.

\section{Statistical features}

Statistical features such as mean, variance, standard deviation etc. are obtained from contents of an image. 
Geometrical features

Geometric objects are produced by using entities such as lines, points, polylines, arcs, etc.
Features may be corners, edges, blobs and so on.

Table 1: performance evaluation of the various schemes used to classify digital images

\begin{tabular}{|c|c|c|c|c|}
\hline Work & Feature & $\begin{array}{c}\text { Feature } \\
\text { dimension }\end{array}$ & Data set & $\begin{array}{c}\text { Classification } \\
\text { accuracy }\end{array}$ \\
\hline [5] & $\begin{array}{l}\text { Histogram features, } \\
\text { multi-fractal spectrum } \\
\text { features, regression } \\
\text { model fitness features }\end{array}$ & 24 & $\begin{array}{l}\text { Columbia University } \\
\text { Image Database, } \\
\text { Dresden, Image } \\
\text { database }\end{array}$ & $98.69 \%$ \\
\hline [6] & Fractal dimension & 20 & $\begin{array}{l}\text { Columbia University } \\
\text { Image Database, } \\
\text { www.3dshop.com, } \\
\text { www.raph.com }\end{array}$ & $92 \%$ \\
\hline [7] & $\begin{array}{l}\text { Peak of histogram, } \\
\text { mean value of the } \\
\text { difference between } \\
\text { the peak and its } \\
\text { left and its right } \\
\text { values, variance } \\
\text { of the histogram }\end{array}$ & 9 & $\begin{array}{l}\text { Columbia University } \\
\text { Image Database. }\end{array}$ & $99.43 \%$ \\
\hline [3] & $\begin{array}{l}\text { Multifractal spectrum } \\
\text { features of PRNU }\end{array}$ & 8 & $\begin{array}{l}\text { Columbia University } \\
\text { Image Database. }\end{array}$ & $98.99 \%$ \\
\hline [8] & $\begin{array}{l}\text { Image Contour } \\
\text { Information }\end{array}$ & 46 & $\begin{array}{l}\text { Columbia University } \\
\text { Image Database. }\end{array}$ & $90.36 \%$ \\
\hline [9] & Wavelet based features & 330 & $\begin{array}{l}\text { Columbia University } \\
\text { Image Database. }\end{array}$ & $87.6 \%$ \\
\hline [4] & Fractal geometry & 30 & $\begin{array}{l}\text { www.3dshop.com } \\
\text { www.raph.com } \\
\text { Washington Image } \\
\text { Database }\end{array}$ & $91.2 \%$ \\
\hline$[10]$ & Residual pattern noise & 15 & $\begin{array}{l}\text { Natural images taken } \\
\text { from various digital } \\
\text { cameras,scanner } \\
\text { images taken from } \\
\text { different scanner } \\
\text { models, computer } \\
\text { generated images are } \\
\text { download from the } \\
\text { following links: } \\
\text { www.3dlinks.com, www. } \\
\text { irtc.com, www.raph.com, } \\
\text { www.digitalrepose.com, } \\
\text { www.maxon.net } \\
\text { www.realsoft.com }\end{array}$ & $85.9 \%$ \\
\hline
\end{tabular}




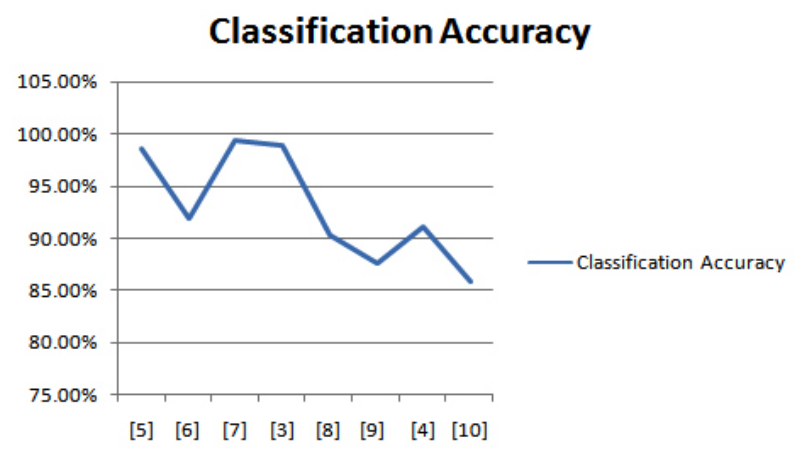

Fig. 1: Performance Evaluation

Organization of the paper is as follows: Section 2 describes the differences between images of two classes. Data set used by various authors and performance evaluation is discussed in Section 3.

\section{Differences between photographic images and computer generated photorealistic images}

The differences between the images of two kinds are given below ${ }^{8}$.

\section{Acquisition difference}

photographic images are taken from various digital cameras where CG images are generated using graphics software packages to achieve realism. The process used to generate natural and CG images are analyzed.

\section{Illumination source difference}

light from the surface of the objects captured by a camera is reflected and passed through the lens, filters and CFA (Color Filter Array) and lastly reaches an array of charged couple device. In computer graphics, the object is simulated by specifying shape of the object, its orientation and surface of colors or textures. In addition to this, user has to specify viewer's position and view direction. Finally, the software will calculate the components of the entity that can be perceived by the viewer and only the visible portion is displayed.

\section{Object model difference}

photographic images are the replica of the scene. In computer graphics, objects are represented by using polygons and the color for the object is set synthetically.

\section{Presentation difference}

The above three differences finally results in the presentation differences of two image kinds. Distribution of the color in photographic images is not saturated where as in CG images are saturated to an extent.

\section{Data Set and Performance Evaluation}

Table 1 shows the performance of various proposed methods to distinguish between natural images and CG images.

\section{CONCLUSION}

In this paper, comparative study of proposed technique is used to classify digital images such as natural and computer graphics images were presented. From the analysis of existing schemes, it is found that the authors have used the features and their combinations which were discussed in introduction section to classify natural images and CG images. Modern day computer graphics are capable of generating highly photorealism images. For this reason, sometimes it is very challenging to discriminate $\mathrm{CG}$ and photographic images. 


\section{REFERENCES}

1. Ahmed Talib, Massudi Mahmuddin, Husniza Husni and Loay E. George, "Influencing Factors on Classfication of Photographic and Computer Generated Images", in Jrnl. Of Computing, Vol. 4, Issue 2, Feb 2012, pp. 74-79.

2. Dongmei Chen, Jianhua Li, Shilin Wang, Shenghong Li, "Identifying Computer Generated and Digital Camera Images Using Fractional Lower Order Moments", in 4th IEEE conf. on Industrial Electronics and Applications, pp. 230-235, 2009.

3. Fei Peng, Jiaoling Shi, Ming Long, "Identifying photographic images and photorealistic computer graphics using multifractal spectrum features of PRNU", in IEEE Intl. Conf. on Multimedia and Expo, DOI: 10.1109/ ICME.2014.6890296

4. PAN Feng, CHEN JiongBin, HUANG JiWu, "Discriminating between photorealistic computer graphics and natural images using fractal geometry", in Science in China Series F: Information Sciences, Vol. 52, Issue 2, pp. 329-337, 2009.

5. Fei Peng, Die-lan Zhou, Min Long, Xing-ming Sun, "Discrimination of natural images and computer generated graphics based on multi-fractal and regression analysis", in Int. J. Electron.Commun., Vol. 71, 2017, pp. $72-$ 81.
6. Yingda Lv, Xuanging Shen, Guofu Wan, HaiPeng Chen, "Blind Identification of Photorealistic Computer Graphics Based on Fractal Dimensions", in Int. Conf. on Computer, Commun. and Inf. Tech., pp. 257260, 2014.

7. Fei Peng, Die-lan Zhou, "Discriminating natural images and computer generated graphics based on the impact of CFA interpolation on the correlation of PRNU", in Elsevier J. of Digital Investigation, Vol. 11, 2014, pp. 111-119.

8. Shaojing Fan, Rangding Wan, Yongping Zhang, Ke Guo, "Classifying Computer Generated Graphics and Natural Image Based on Image Contour Information", in Jrnl. Of Inf. \& Computational Science 9: 10, 2012, pp. 2877-2895.

9. Rong Zhang, Randing Wang, "Distinguishing Photorealistic Computer Graphics from Natural Images by Imaging Features and Visual Features", in IEEE IntI. Conf. on Electronics, Communications and Control, 2011, pp. 226-229.

10. Nitin Khanna, George T.-C. Chiu, Jan P. Allebach, Edward J. Delp, "Forensic techniques for classifying scanner, computer generated and digital camera images", in IEEE Intl. Conf. on Acoustics, Speech, and Signal Processing, 2008, pp. 1653-1656. 